\title{
ВОПРОСЫ ТЕОРИИ И МЕТОДОЛОГИИ ИЗУЧЕНИЯ ПРИЧИН ТЕРРИТОРИАЛЬНЫХ РАЗЛИЧИЙ ПРЕСТУПНОСТИ В РАБОТАХ СОВЕТСКИХ КРИМИНОЛОГОВ
}

Аннотация: В статье представлен краткий исторический и сравнительный анализ основных подходов криминологов Грузинской, Латвийской, Литовской и Эстонской Советских Сочииалистических Республик бывшего СССР к изучению такого феномена как территориальные различия показателей преступности и их причин. Описана теоретическая сущность и методологическая составляющая таких подходов как: сравнительный криминологический анализ, изучение географии преступности и ее динамики, системный подход к пониманию территориальных (пространственных) структур (населенных пунктов, административньх районов, отдельных регионов) и др. В статье использован сравнительно-исторический метод исследования подходов научных школ и отдельньх криминологов республик бывшего СССР (1970-1980-е гг.) к изучению причин территориальных различий преступности В работе раскрыты исходные предпосылки и последующая преемственность в расширении и углублении теоретико-методологической базы изучения причин территориальных различий преступности. Так, уже к сер. 1980-х г2. советскими криминологами была теоретически обоснована необходимость понимания территориальных (региональных) и поселенческих структур в качестве своеобразных сложных социально-экономических систем. При этом недостатки и противоречия, возникающие в процессе функционирования подобных систем, неизбежно должны влиять и на показатели преступной активности их населения.

Abstract: The article provides a brief historical and comparative analysis of the main approaches of the criminologists of the Georgian, Latvian, Lithuanian, and Estonian Soviet Socialist Republics of the former USSR towards territorial differences in crime markers and their causes. The author describes theoretical nature and methodological elements of the approaches, such as comparative criminological analysis, studies of geography of crimes and their dynamics, systemic approaches towards territorial (area-related) structures (residential structures, administrative regions, certain regions), etc. The article involves comparative historical method for the studies of approaches of scientific schools and certain criminologists of the former USSR (1970s-1980s) towards studying the causes of territorial differences in crime. The article contains analysis of initial prerequisites and further approaches towards widening and deepening of the scope of territorial and methodological basis for the studies of the causes of territorial differences in crime. For example, by the mid-1980s the Soviet criminologies have theoretically substantiated the need to understand territorial (regional) and residential structures as types of complicated social and economic structures. At the same time the complications and contradictions in the functioning of such systems should inevitably influencing the markers of the criminal activities of the population. Ключевые слова: Советская криминология, территориальные различия преступности, Грузинская ССР, Латвийская ССР, Литовская ССР, Эстонская ССР, сравнительный криминологический анализ, география преступности, системный подход, причины преступности.

Keywords: Soviet criminology, territorial differences in crime, Georgian SSR, Latvian SSR, Lithuanian SSR, comparative criminological analysis, geography of crime, systemic approach, causes of crime.

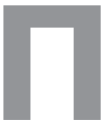

роблема причин территориальных различий показателей преступности является одной из ключевых в криминологии, поскольку от результатов ее разрешения зависит ответ на вопрос: в чем же заключаются, собственно, причины преступности в целом? Поэтому вполне закономерно, что уже на этапе осмысления самого феномена преступности как общественного явления стала осознаваться и необходимость изучения факторов, порождающих различия показателей преступной активности населения отдельных территорий ${ }^{1}$.

\footnotetext{
${ }^{1}$ Бахарев Д.В. Вопрос о причинах преступности в работах русских писателей и публицистов 2-й половины XIX века // История
} 
В России рассмотрение причин преступности в территориальном аспекте началось фактически одновременно с зарождением криминологической науки в целом, и продолжалось на всем этапе ее становления в качестве самостоятельной отрасли знаний ${ }^{2}$. В период расцвета советской криминологии (1970-1980-е гг.) изучение причин территориальной дифференциации преступности происходило в рамках такого достаточно полно и всесторонне развитого направления как изучение теории и методологии исследования территориальных различий преступности. Наиболее серьезный вклад в изучение данной проблемы внесли многолетние широкомасштабные исследования, осуществленные коллективом сотрудников Всесоюзного института по изучению причин и разработке мер предупреждения преступности. Полученные результаты были отражены в целом ряде публикаций ${ }^{3}$. Менее известны, к сожалению, работы коллективов ученых ряда республик Советского Союза (Грузинская, Латвийская, Литовская и Эстонская ССР), оставивших очень серьезный след как в области развития теории изучения причин территориальных различий преступности, так и в сфере формирования методологии подобных исследований.

Литовские ученые одними из первых внесли свой вклад в формирование сравнительного криминологического анализа, сущность которого заключается в «качественном сравнении характера преступности и социальных условий для различных территориальных общностей» ${ }^{4}$. В рамках данного направления сложилось несколько основных подходов, один из которых - изучение динамики географии преступности. Его

государства и права. 2012. №4. С.25-28; Он же. Причины преступности как политико-философская категория в работах деятелей французского Просвещения // История государства и права. 2012. №18. C.6-8.

${ }^{2}$ См. подр.: Бахарев Д.В. Взгляды русских мыслителей XVIII века на проблему преступности (от И.Т. Посошкова до А.Н. Радищева) // Политика и общество. 2011. №11. С.141-142; Он же. Изучение причин территориальных различий преступности в эпоху становления отечественной криминологической мысли (историко-библиографический очерк) // Современное право. 2012. №10. С.160-164.

${ }^{3}$ См., напр.: Влияние социальных условий на территориальные различия в преступности. - М., 1977; Влияние социальных условий на преступность. Сборник научных трудов. - М., 1983; Сахаров А.Б. Опыт изучения влияния социальных условий на территориальные различия преступности // Социологические исследования. 1977. №1. С.75-84; Территориальные различия преступности и их причины // Вопросы борьбы с преступностью. - М., 1988. № 46. С.160-166; Территориальные различия преступности и их причины. Сборник научных трудов - М., 1988.

${ }^{4}$ Мазин Е.Н. Основные направления исследований территориальных различий преступности // Сборник научных работ. - Вильнюс, 1980. Вып. 6. С. 207-208. автор (А.А. Янаускас) подверг классификации города и районы Литовской ССР, разбив их на три группы: с низким, средним и высоким уровнем преступности. Применив затем метод картографирования автор разбил территорию республики на более-менее однородные по показателям преступности зоны и сопоставил их с основными социально-экономическими процессами, происходившими в тот период в Литве 5 .

В соответствии с подходом, разработанным теперь уже латвийскими исследователями (Э.Е. Дзенис и Г.Г. Менберг), сравнительному криминологическому анализу были подвергнуты уже не административно-территориальные единицы Латвии, а выделенные авторами укрупненные местные экономические районы, составлявшие компактно расположенные и экономически взаимосвязанные дробные территориальные образования ${ }^{6}$. Кроме того, авторами была разработана типология городов республики, основанная на следующих признаках: иерархический ранг, народно-хозяйственное значение региона, на территории которого город расположен, величина городского поселения и динамика численности населения в нем. В каждом из выделенных типов городов были проанализированы социально-экономические условия, включая миграционные процессы, после чего были сделаны некоторые выводы о закономерностях территориальных различий преступности в республике?

Серьезный вклад в исследование данной проблематики был внесен грузинскими учеными. В качестве отдельного аспекта в исследовании закономерностей формирования территориальных различий преступности они также выделили изучение географии преступности, под которой, в свою очередь, понимали научное направление, преследующее цель дифференцированного пространственного анализа преступности по заранее определенным параметрам на основе расчленения всей исследуемой территории на регионы, более или менее однородные в социально-экономическом, демографическом, культурно-историческом и природно-геогра-

\footnotetext{
${ }^{5}$ См. подробнее: Янаускас А. Некоторые результаты сравнительного исследования уровня, динамики и структуры преступности по городам Литовской ССР // Материалы научно-практической конференции по проблемам борьбы с преступностью в городах областного подчинения. - Липецк, 1970. С. 228-231; Янаускас A. О закономерностях в динамике преступности и их изучении // Изучение и предупреждение преступности. Сборник научных работ. Вып. 4. - Вильнюс, 1971. С.15-23.

${ }^{6}$ Дзенис Э.Н., Менберг Г.Г. Социально-географические аспекты изучения преступности в Латвийской ССР // Криминологические исследования. Вып.1 - Рига, 1974. С.60-64.

7 Дзенис Э.Н., Менберг Г.Г. Указ. соч. С.67-69.
} 
DOI: 10.7256/1811-9018.2014.10.13015

При цитировании этой статьи сноска на доі обязательна

\section{Право и политика $10(178) \cdot 2014$}

фическом отношении ${ }^{8}$. Соответственно, как полагали авторы, для изучения географии преступности необходим учет почти всех более или менее значимых позитивных экономических и социально-культурных процессов, поскольку, если «на определенных участках территории республики природные, экономические, социально-демографические, исторические, культурные и этнические процессы существенно различаются по своей интенсивности и характеру, то на этих же участках преступность, по всей вероятности, также должна сильно различаться»?.

Более детальный анализ территориальных различий преступности позволил авторам выделить отдельные регионы республики, отличающиеся повышенным уровнем преступности по сравнению со средним по республике. В число таких регионов вошли как крупные города (Кутаси, Батуми и Поти), так и горные районы (Восточный Кавкасиони и Юго-Осетинская АО), а также приморский район - Абхазская АССР. Высокие показатели уровня преступности в последнем регионе вообще и в г.Сухуми, в частности, были объяснены тем, что «данный коэффициент рассчитывается на постоянное население, а в летний сезон там скапливается вдвое-втрое больше людей и нередко субъектом преступления становятся приезжие...» ${ }^{10}$. Высокая преступность Юго-Осетинской АО и, в частности ее столицы - г.Цхинвали, авторами объяснялась быстрым ее ростом за счет сельских мигрантов и трудностями их адаптации. Горный сельский район Восточный Кавкасиони является зоной транзитных переездов, что также, по мнению авторов, могло сказаться на высоких показателях преступности в нем ${ }^{11}$.

Дальнейшее изучение причин территориальных различий преступности дало возможность грузинским криминологам отметить, что по мере роста доминирования городского образа жизни в регионах повышаются и показатели соотношения между коэффициентами пре-

\footnotetext{
${ }^{8}$ Габиани А., Гачичеладзе Р., Дидебулидзе М. Об основных принципах пространственного анализа преступности (на примере Грузинской ССР) // Актуальные вопросы предупреждения правонарушений. Труды Научно-исследовательской лаборатории социологии преступности МВД ГССР. - Тбилиси, 1981. Вып. 1. С.10.

${ }^{9}$ Габиани А., Гачичеладзе Р., Дидебулидзе М. Об основных принципах пространственного анализа преступности (на примере Грузинской ССР) // Актуальные вопросы предупреждения правонарушений. Труды Научно-исследовательской лаборатории социологии преступности МВД ГССР. - Тбилиси, 1981. Вып. 1. С.13.

${ }^{10}$ Габиани А.А., Гачечиладзе Р.Г. Некоторые вопросы географии преступности. По материалам Грузинской ССР. - Тбилиси, 1982. C.116.

${ }^{11}$ Там же. С.116.
}

ступности в городской и сельской местности (в пользу города) и наоборот. В тех регионах, где имелась относительно развитая сеть городов, отмечалось разительное отличие сельской местности как по концентрации объектов приложения несельскохозяйственного труда (на которых нередко заняты маятниковые мигранты из сельской местности), так и по количеству объектов досуга и общественного питания, привлекающих лиц, особенно молодого возраста со всего региона. В итоге, коэффициент городской преступности на данной территории значительной превышал коэффициент сельской преступности ${ }^{12}$.

Кроме того, как считали грузинские специалисты, объяснить картину различий в уровне преступности по регионам можно и теми процессами, которые имеют место в экономической жизни. «Если, к примеру, взять такой экономический показатель как плотность хозяйственной деятельности, то окажется, что Самегрело и Гурия... имеют коэффициент хозяйственной освоенности территории - 15 (по данным 1975г.), при среднереспубликанском показателе - 17. Шида-Картли - 11,3, Квемо-Картли - 10,9. А в тех регионах, где отношение коэффициента «городской» преступности к коэффициенту «сельской» преступности существенно ниже среднерегионального показателя - Восточный Кавкасиони, Западный Кавкасиони, коэффициент хозяйственной освоенности территории равен для первого - 0,5-2,8, для второго - 1,8 . Из этого можно предположить, что отношение коэффициентов «городской» и «сельской» преступности, как и сами коэффициенты, кореллируют с коэффициентом хозяйственной освоенности территории» ${ }^{13}$.

В трудах криминологов из Эстонской ССР и Ленинграда вопросы изучения территориальных различий преступности были представлены, преимущественно, в теоретическом аспекте. В целом, их можно свести к следующим принципиальным моментам:

- географическая среда, (т.е. территориальные особенности регионов), сама по себе, не является причиной, обусловливающей природу общественного строя; она является лишь необходимой предпосылкой социальных различий территориальных общностей, таким образом,

\footnotetext{
${ }^{12}$ Габиани А.А., Гачечиладзе Р.Г., Дидебулидзе М.И. Преступность в городах и сельской местности. Конкретно-криминологическое и социально-географическое исследование по материалам Грузинской ССР. - Тбилиси, 1985. С.108.

${ }^{13}$ Габиани А.А., Гачечиладзе Р.Г., Дидебулидзе М.И. Преступность в городах и сельской местности. Конкретно-криминологическое и социально-географическое исследование по материалам Грузинской ССР. - Тбилиси, 1985. С.110.
} 
DOI: $10.7256 / 1811-9018.2014 .10 .13015$

При цитировании этой статьи сноска на dоі обязательна

Правовая и политическая мысль

методы регионального анализа (включая методы исследования территориальных различий преступности), являются, по сути, методами социального анализа;

- систематизация социальных факторов, влияющих на преступность, должна базироваться на общесоциологической теории исторического материализма, с точки зрения которой, в роли факторов, обусловливающих соблюдение или нарушение населением уголовно-правовых запретов, прежде всего, выступают социальные свойства людей, характеризующие их положение в сфере производства: социально-классовая принадлежность, место в профессионально-квалифицированной структуре общественного труда, должностное положение, роль в организации общественного труда, степень участия в творческом труде, уровень заработной платы и т.д.; вместе с тем, общественная жизнь людей протекает не только в сфере производства, но и в сфере политики, культуры, быта и потребления, которые в совокупности со сферой производства исчерпывают все области общественной жизни;

- отсюда, преступность как всякое социальное явление, будучи одной из характеристик состояния общественного организма, определяется всей совокупностью факторов, характеризующих все вышеперечисленные области общественной жизни, причем совокупностью, воздействующей на преступность не отдельными своими элементами (например, образованием, уровнем дохода, жилищным положением и т.д.), а интегрировано, всей системой факторов, взаимодействующих между собой; следовательно, ни одно из существующих в обществе противоречий (на социальном уровне) непосредственно не детерминирует существование преступности, а лишь создает, наряду с другими факторами и противоречиями, объективную возможность их существования;

- несмотря на то, что общество представляет собой органическое единство экономических, политических, социально-культурных отношений, развивающихся в определенных демографических условиях, роль экономических факторов в социальном развитии, в том числе и в развитии преступности как одного из общественных явлений, является определяющей, поскольку развитие народного хозяйства и изменение структуры общественного труда оказывает решающее влияние на структуру рабочих мест и, тем самым, в конечном счете, предопределяет социальную структуру населения; в свою очередь, установив социально-классовое положение так называемого «среднестатистического» индивида, то есть его принадлежность к тем или иным общественным классам или внутриклассовым социаль- ным группам, можно установить все его социальные характеристики - примерные образование, квалификацию, размер заработной платы, уровень культуры, круг общения и т.д.; таким образом, изменения в производственной сфере образуют, изменяя социальную структуру общества, материальную основу всех прочих социальных изменений;

- региональный криминологический анализ представляет собой содержательное сравнение двух или более территориальных общностей с присущими им уровнями и структурами преступности, произведенное на основе сопоставления соответствующих систем социальных, экономических, политических, демографических и т.д. факторов; отсюда регион понимается как сложная система, изменения, происходящие в которой, вызываются не только что оказанным на них существенным воздействием, а опосредованы целой цепочкой воздействий и ответных реакций системы на протяжении прошлого периода времени;

- для эффективного управления такими системами, необходимо знать, чем определяется их поведение; следовательно, необходимо определить набор факторов, определяющих динамическое поведение сложных систем, отсюда на первый план выходит одна из сложнейших задач криминологической науки - разработка методов, позволяющих количественно анализировать динамическое поведение сложных систем, взаимодействие которых и образует причинный социально-экономический комплекс преступности ${ }^{14}$.

В свою очередь, Э. Раска, обратившись к вопросу о целесообразности использования в процессе территориальных исследований социальной обусловленности преступности географических методов, а также обратив внимание и на иные принципиальные моменты, выдвинул следующие предложения:

- изучение закономерностей территориальной локализации (географии) преступности представляет собой сугубо описательную исследовательскую процедуру, которая не в состоянии непосредственно затрагивать глубинные структуры феномена преступности; соответственно, лишь комплексное изучение а) территориальной локализации (географии) преступности и б) характеристик социального пространства и образа жизни людей в соответствующих зонах локализации

\footnotetext{
${ }^{14}$ Спиридонов Л., Лепс А. Теоретические вопросы изучения территориальных различий преступности // Теоретические проблемы изучения территориальных различий преступности. Ученые записки Тартуского ун-та: Труды по криминологии. - Тарту, 1985, Вып. 725. С.4-18.
} 
DOI: 10.7256/1811-9018.2014.10.13015

При цитировании этой статьи сноска на dоі обязательна

\section{Право и политика $10(178) \cdot 2014$}

преступности может дать более или менее целостное представление об исследуемом явлении в конкретных условиях социального пространства;

- особенно перспективными являются сравнительные исследования преступности и ее социальных условий в экстремальных зонах локализации, поскольку подобные исследования являются, по сути, естественными экспериментами, в процессе которых открываются возможности довольно точного определения того, какими изменениями в преступности социальноэкономическая пространственная система реагирует на изменение ее отдельных параметров, т.е. определить, какие криминологически значимые социальные последствия повлекут за собой изменения определенных условий жизнедеятельности людей ${ }^{15}$;

- структура детерминант преступности изменяется по мере развития и постоянного изменения самого общества, поэтому то, что в этой структуре сегодня является ведущим, определяющим, уступит, быть может, завтра свое место другим обстоятельствам; в связи с этим малопродуктивным является подход, при котором проблема преступности сводится лишь к тому, чтобы в конкретных условиях исследуемой территории выявить, что именно порождает преступность, в какой сфере социальной жизни людей скрываются ее корни;

- преимущества территориального подхода к проблеме преступности заключаются в возможности ее рассмотрения в качестве функции живого общественного организма и изучения эмпирических проявлений преступности в разрезе территориально-пространственных систем, в результате чего криминолог получает реальную возможность оце- нить отражение социальных свойств общественного организма или качество условий жизнедеятельности общественно организованного человека в характеристиках преступности, в порождении преступной активности населения;

- в роли такого показателя преступность определяет прямое или косвенное влияние различных компонентов общественного организма, среди которых центральное место принадлежит населению, которое рассматривается как объект и субъект исторического процесса производства, распределения и потребления материальных и духовных благ; население, при наличии определенных условий, продуцирует и контингент лиц, реализующих криминогенный потенциал общественного организма в конкретную преступность;

- в результате, уровень преступной активности населения соразмерен криминогенному потенциалу общества, рассматриваемой территориально-пространственной системы, основным источником которого является население, дифференцирующееся по демографическим, социальным, профессиональным группам, социальная, a, следовательно, и криминальная активность которых не является одинаковой ${ }^{16}$.

Приведенный выше анализ теоретических и методологических позиций ученых ряда республик Советского Союза по вопросу о причинах территориальных различий преступности далеко не в полной мере иллюстрирует глубину научной проработки данной проблемы. Он призван лишь, в значительной мере, дать исходный ориентир современному исследователю, приступающему к поиску своих путей решения этой многогранной криминологической задачи.

\section{Библиография:}

1. Бахарев Д.В. Вопрос о причинах преступности в работах русских писателей и публицистов 2-й половины XIX века // История государства и права. 2012. №4. С.25-28.

2. Бахарев Д.В. Причины преступности как политико-философская категория в работах деятелей французского Просвещения // История государства и права. 2012. №18. С.6-8.

3. Бахарев Д.В. Взгляды русских мыслителей XVIII века на проблему преступности (от И.Т. Посошкова до А.Н. Радищева) // Политика и общество. 2011. №11. С.136-142.

4. Бахарев Д.В. Изучение причин территориальных различий преступности в эпоху становления отечественной криминологической мысли (историко-библиографический очерк) // Современное право. 2012. №10. С.160-164.

5. Влияние социальных условий на территориальные различия в преступности. - М., 1977. 140c.

6. Влияние социальных условий на преступность. Сборник научных трудов. - М., 1983. 123c.

7. Сахаров А.Б. Опыт изучения влияния социальных условий на территориальные различия преступности // Социологические исследования. 1977. №1. С.75-84.

\footnotetext{
15 Раска Э. Процедуры территориального исследования социальной обусловленности преступности // Теоретические проблемы изучения территориальных различий преступности. Ученые записки Тартуского ун-та: Труды по криминологии. - Тарту, 1985, Вып. 725. С.35-38.
} ${ }^{16}$ Раска Э.Э. Преступность как показатель состояния социально-
го пространства (К вопросу об обосновании территориального
подхода к изучению преступности) // Теоретические проблемы
изучения территориальных различий в преступности: Террито-
риальные различия в социальных условиях преступности. Труды
по криминологии. - Тарту, 1987, Вып. 761. С.22-26. 
DOI: $10.7256 / 1811-9018.2014 .10 .13015$

При цитировании этой статьи сноска на dоі обязательна

Правовая и политическая мысль

8. Территориальные различия преступности и их причины // Вопросы борьбы с преступностью. № 46. - М., 1988. С.160-166.

9. Территориальные различия преступности и их причины. Сборник научных трудов-М., 1988. 104c.

10. Мазин Е.Н. Основные направления исследований территориальных различий преступности // Сборник научных работ. - Вильнюс, 1980. Вып. 6. С. 206-223.

11. Янаускас А. Некоторые результаты сравнительного исследования уровня, динамики и структуры преступности по городам Литовской ССР // Материалы научно-практической конференции по проблемам борьбы с преступностью в городах областного подчинения. - Липецк, 1970. С. 228-231.

12. Янаускас А. О закономерностях в динамике преступности и их изучении // Изучение и предупреждение преступности. Сборник научных работ. Вып. 4. - Вильнюс, 1971. С.15-23.

13. Дзенис Э.Н., Менберг Г.Г. Социально-географические аспекты изучения преступности в Латвийской ССР // Криминологические исследования. Вып.1-Рига, 1974. С.60-64.

14. Габиани А., Гачичеладзе Р., Дидебулидзе М. Об основных принципах пространственного анализа преступности (на примере Грузинской ССР) // Актуальные вопросы предупреждения правонарушений. Труды Научно-исследовательской лаборатории социологии преступности МВД ГССР. - Тбилиси, 1981. Вып. 1. С.8-30.

15. Габиани А.А., Гачечиладзе Р.Г. Некоторые вопросы географии преступности. По материалам Грузинской ССР. - Тбилиси, 1982. 143c.

16. Габиани А.А., Гачечиладзе Р.Г., Дидебулидзе М.И. Преступность в городах и сельской местности. Конкретнокриминологическое и социально-географическое исследование по материалам Грузинской ССР. - Тбилиси, 1985. 141с.

17. Спиридонов Л., Лепс А. Теоретические вопросы изучения территориальных различий преступности // Теоретические проблемы изучения территориальных различий преступности. Ученые записки Тартуского ун-та: Труды по криминологии. - Тарту, 1985, Вып. 725. С.3-18.

18. Раска Э. Процедуры территориального исследования социальной обусловленности преступности // Теоретические проблемы изучения территориальных различий преступности. Ученые записки Тартуского ун-та: Труды по криминологии. - Тарту, 1985, Вып. 725. С.34-63.

\section{References (transliterated):}

1. Bakharev D.V. Vopros o prichinakh prestupnosti v rabotakh russkikh pisatelei i publitsistov 2-i poloviny XIX veka // Istoriya gosudarstva i prava. 2012. №4. S.25-28.

2. Bakharev D.V. Prichiny prestupnosti kak politiko-filosofskaya kategoriya v rabotakh deyatelei frantsuzskogo Prosveshcheniya // Istoriya gosudarstva i prava. 2012. №18. S.6-8.

3. Bakharev D.V. Vzglyady russkikh myslitelei XVIII veka na problemu prestupnosti (ot I.T. Pososhkova do A.N. Radishcheva) // Politika i obshchestvo. 2011. №11. S.136-142.

4. Bakharev D.V. Izuchenie prichin territorial'nykh razlichii prestupnosti v epokhu stanovleniya otechestvennoi kriminologicheskoi mysli (istoriko-bibliograficheskii ocherk) // Sovremennoe pravo. 2012. №10. S.160-164.

5. Sakharov A.B. Opyt izucheniya vliyaniya sotsial'nykh uslovii na territorial'nye razlichiya prestupnosti // Sotsiologicheskie issledovaniya. 1977. №1. S.75-84.

6. Mazin E.N. Osnovnye napravleniya issledovanii territorial'nykh razlichii prestupnosti // Sbornik nauchnykh rabot. - Vil'nyus, 1980. Vyp. 6. S. 206-223.

7. Yanauskas A. Nekotorye rezul'taty sravnitel'nogo issledovaniya urovnya, dinamiki i struktury prestupnosti po gorodam Litovskoi SSR // Materialy nauchno-prakticheskoi konferentsii po problemam bor'by s prestupnost'yu v gorodakh oblastnogo podchineniya. - Lipetsk, 1970. S. 228-231.

8. Yanauskas A. O zakonomernostyakh v dinamike prestupnosti i ikh izuchenii // Izuchenie i preduprezhdenie prestupnosti. Sbornik nauchnykh rabot. Vyp. 4. - Vil'nyus, 1971. S.15-23.

9. Dzenis E.N., Menberg G.G. Sotsial'no-geograficheskie aspekty izucheniya prestupnosti v Latviiskoi SSR // Kriminologicheskie issledovaniya. Vyp.1-Riga, 1974. S.60-64.

10. Gabiani A., Gachicheladze R., Didebulidze M. Ob osnovnykh printsipakh prostranstvennogo analiza prestupnosti (na primere Gruzinskoi SSR) // Aktual'nye voprosy preduprezhdeniya pravonarushenii. Trudy Nauchno-issledovatel'skoi laboratorii sotsiologii prestupnosti MVD GSSR. - Tbilisi, 1981. Vyp. 1. S.8-30.

11. Gabiani A.A., Gachechiladze R.G. Nekotorye voprosy geografii prestupnosti. Po materialam Gruzinskoi SSR. - Tbilisi, 1982. 143s.

12. Gabiani A.A., Gachechiladze R.G., Didebulidze M.I. Prestupnost' v gorodakh i sel'skoi mestnosti. Konkretno-kriminologicheskoe i sotsial'no-geograficheskoe issledovanie po materialam Gruzinskoi SSR. - Tbilisi, 1985. 141s.

13. Spiridonov L., Leps A. Teoreticheskie voprosy izucheniya territorial'nykh razlichii prestupnosti // Teoreticheskie problemy izucheniya territorial'nykh razlichii prestupnosti. Uchenye zapiski Tartuskogo un-ta: Trudy po kriminologii. - Tartu, 1985, Vyp. 725. S.3-18.

14. Raska E. Protsedury territorial'nogo issledovaniya sotsial'noi obuslovlennosti prestupnosti // Teoreticheskie problemy izucheniya territorial'nykh razlichii prestupnosti. Uchenye zapiski Tartuskogo un-ta: Trudy po kriminologii. - Tartu, 1985, Vyp. 725. S.34-63. 